17,01

\title{
Процессы переноса заряда в углеродных композитах на основе фуллеренов и терморасширенного графита
}

\author{
(C) В.И. Берёзкин \\ Научно-исследовательский центр экологической безопасности РАН, \\ Санкт-Петербург, Россия \\ E-mail: v.berezkin@inbox.ru
}

(Поступила в Редакцию 29 ноября 2016 г.

В окончательной редакции 15 декабря 2016 г.)

\begin{abstract}
Исследованы кинетические процессы в композиционных материалах на основе фуллеренов и терморасширенного графита при исходных соотношениях компонентов от 1:16 до 16:1 по массе. Образцы получены путем термообработки в вакууме в диффузионно-адсорбционном процессе исходных дисперсных смесей, их дальнейшего холодного прессования и отжига. Показано, что последний практически не влияет на механизмы проводимости, а лишь создает дополнительные дефекты структуры, действующие как электронные ловушки. В целом полученные результаты при использованных соотношениях компонентов позволяют отнести материал к компенсированной металлической системе со структурным беспорядком, в которой перенос заряда при температурах от $4.2 \mathrm{~K}$ до комнатной управляется квантовыми интерференционными явлениями. В области низких температур проявляются эффекты слабой локализации, а в области средних и высоких температур - электрон-электронные взаимодействия.
\end{abstract}

DOI: 10.21883/FTT.2017.07.44611.424

\section{1. Введение}

Углеродные объекты обладают уникальными механическими, оптическими, электронными и другими свойствами, поэтому они давно используются в промышленных масштабах. Непрерывно разрабатываются их новые модификации, что открывает перспективы новых практических приложений. К настоящему времени на основе углерода создано великое множество разнообразных структур и материалов природного, искусственного и синтетического происхождения, в том числе пористых и непористых, монолитных, дисперсных, с пониженной размерностью, реализуются их различные сочетания как друг с другом, так и с неуглеродными материалами (металлическими, керамическими и т.д.). Такое разнообразие обусловлено рядом особенностей данного элемента. Среди них можно отметить способность образовывать различные типы химической связи, обусловленные различной гибридизацией атомов, обеспечивать разный характер и масштаб упорядочения последних, возможность эффективного использования неоднородностей структуры любого уровня (от микро- до макроуровня), создаваемых, например, путем введения атомов примесей, организации развитой пористой структуры, построения композиционных материалов $[1,2]$.

С углеродными объектами связывают сегодня перспективы создания качественно новых материалов, покрытий (упрочняющих, защитных, экранирующих, просветляющих, нелинейно-оптических), компонентов электротехники, элементов электронных устройств и т.д. В частности, разрабатываются структуры, которые могут быть использованы в качестве фотоприемников, светоизлучающих устройств, холодных катодов (полевая эмиссия [3]), сверхпроводников.
Например, сверхпроводимость получена, как хорошо известно [4], в интеркалированных металлами фуллереновых структурах. Однако такие сверхпроводники крайне нестабильны. В воздушной среде они быстро теряют сверхпроводимость вследствие окисления металлических примесей.

В работах [5,6] была представлена технология синтеза и описаны свойства основанных на фуллеренах углерод-углеродных композитов - как легированных, так и нелегированных. В них при введении примеси натрия обнаружена сверхпроводимость (при температурах $T \leq 15 \mathrm{~K}$ ), на которую воздушная среда практически не оказывает никакого влияния. Для синтеза исходные смеси, состоящие из поликристаллических порошков $\mathrm{C}_{60}$, углеводородных связующих веществ (нафталин $\mathrm{C}_{10} \mathrm{H}_{8}$ и др.) и соединений, содержащих легирующие элементы, подвергаются воздействию высоких давлений и температур. В результате фуллерены и введенные примесные элементы оказываются размещенными в углеродной матрице, причем химически связываются с ней.

В работе [7] были предложены аналогичные нелегированные композиционные материалы, полученные по иной технологии и при использовании другого связующего вещества-матрицы. Здесь для формирования углеродной матрицы применялся терморасширенный графит (ТРГ), а действие повышенных температур и давлений разделялось во времени. В данных материалах были измерены некоторые электротранспортные параметры.

Целью настоящей работы является выяснение механизмов переноса заряда в структурах, синтезированных в [7]. Для этого исследуются их электрические и гальваномагнитные свойства, а именно: измерены и проанализированы температурные зависимости удельного 


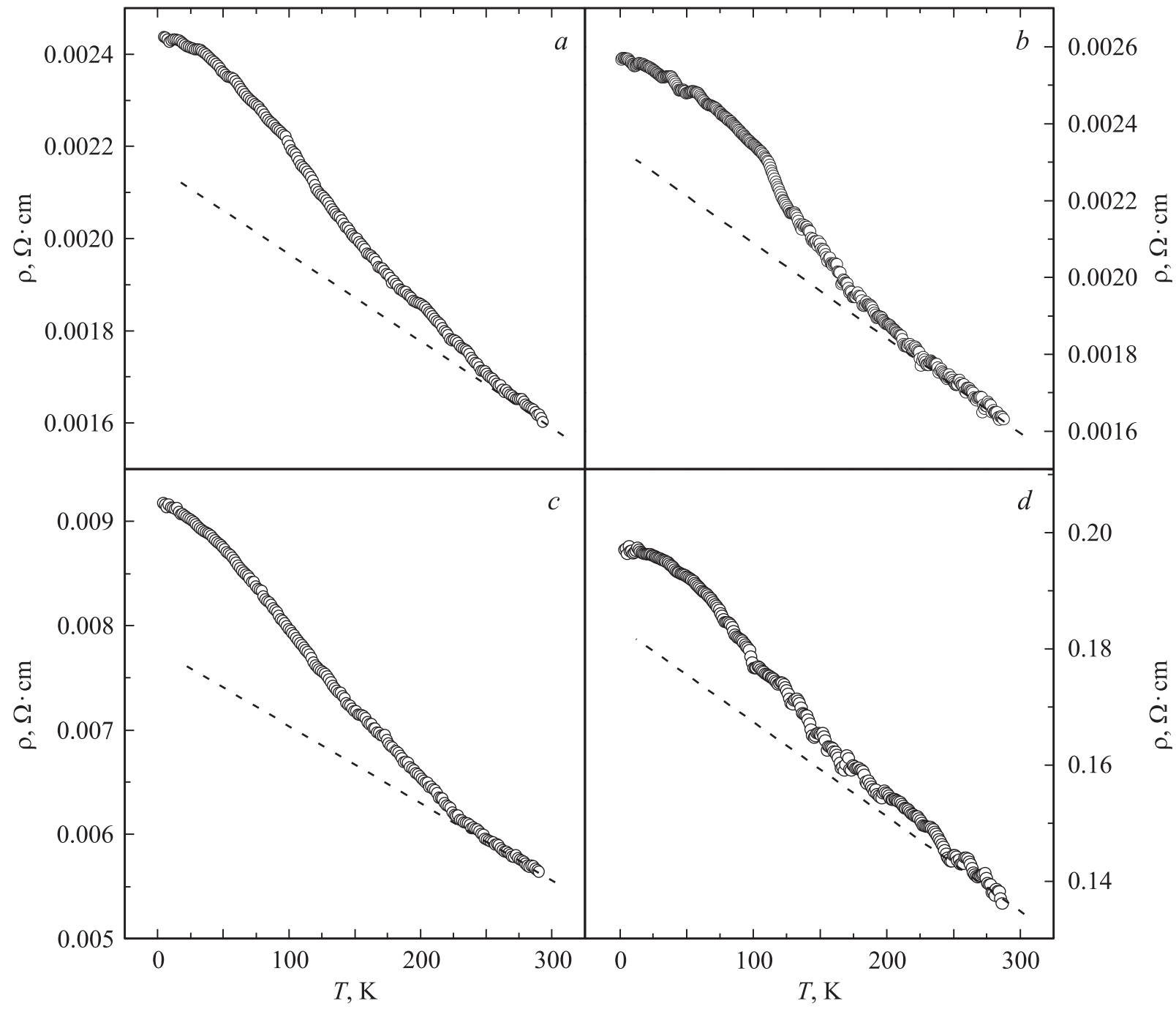

Рис. 1. Температурные зависимости удельного электросопротивления некоторых отожженных образцов при различных соотношениях компонентов. $a-$ образец без $\mathrm{C}_{60}$, т. е. чистый прессованный ТРГ; $b-$ образец с соотношением $\mathrm{C}_{60}: \mathrm{TP}=1: 8$; $c$ - образец состава $\mathrm{C}_{60}:$ ТРГ $=1: 1 ; d-$ образец $\mathrm{C}_{60}:$ ТРГ $=8: 1$. Штриховыми прямыми линиями обозначен начальный (при высоких температурах) наклон кривых.

электросопротивления, зависимости от напряженности магнитного поля постоянной Холла и магнетосопротивления при разных температурах образцов.

\section{2. Образцы и методика экспериментов}

Для синтеза образцов использованы поликристаллические порошки $\mathrm{C}_{60}$, а в качестве связки, как отмечено выше, применялся ТРГ. Исходные дисперсные смеси $\mathrm{C}_{60}+$ ТРГ обрабатывались в течение нескольких часов в вакуумном диффузионно-адсорбционном процессе при температурах $550-650^{\circ} \mathrm{C}$, затем при комнатной температуре $\left(T=T_{\text {room }}\right)$ они прессовались при давлении $0.7 \mathrm{GPa}$ в пластины диаметром $13 \mathrm{~mm}$ и толщиной $\sim 1 \mathrm{~mm}$. Исследовалось два типа образцов: отожженные и неотожженные. В первом случае готовые пластины отжигались в вакууме (также в течение нескольких часов и при температурах $\left.550-650^{\circ} \mathrm{C}\right)$. Во втором случае пластины использованы непосредственно после прессования. Более подробно технология описана в [7].

Получены материалы при девяти различных исходных соотношениях $\mathrm{C}_{60}$ и ТРГ, а именно: при $\mathrm{C}_{60}: \mathrm{TP}=1: 16$; $1: 8 ; 1: 4 ; \ldots ; 16: 1$ по массе. Для сравнения получен также материал без $\mathrm{C}_{60}$, т.е. из чистого ТРГ. Из пластин вырезались образцы нужной формы. С помощью стандартных четырехзондовых методик были измерены зависимости удельного электросопротивления $\rho$ от температуры в диапазоне от $T=4.2 \mathrm{~K}$ до $T_{\text {room }}$, зависимости от напряженности магнитного поля $H$ постоянной Холла $R_{H}$ и магнетосопротивления $\Delta \rho / \rho=[\rho(H, T)-\rho(0, T)] / \rho(0, T)$ измерялись в диапазоне $H=0-25 \mathrm{kOe}$ при двух фиксированных температуpax образцов: $T=77$ и $300 \mathrm{~K}$. 


\section{3. Результаты экспериментов}

Предварительный анализ полученных данных позволил сделать вывод [7], что между фуллеренами и окружением образуются ковалентные связи, материал в целом получается достаточно однородным, характер кривых $\rho(T)$ после отжига не меняется, как и внешний вид образцов.

На рис. 1 показаны типичные зависимости $\rho(T)$, наблюдаемые в отожженном материале. Представлены кривые для образцов из чистого ТРГ (т.е. без $\mathrm{C}_{60}$ ) и композитов с относительно малым, средним и большим содержанием фуллеренов. Пористость образцов учтена по методике, описанной в [7]. Видно, что удельное сопротивление материала из чистого ТРГ минимально, а с увеличением доли фуллеренов оно растет. Во всех образцах имеет место рост величины $\rho$ при снижении температуры измерения, при этом температурная зависимость слабая: во всем диапазоне $\rho$ изменяется в среднем примерно в 1.5 раза. На такую же величину удельное сопротивление увеличивается в результате
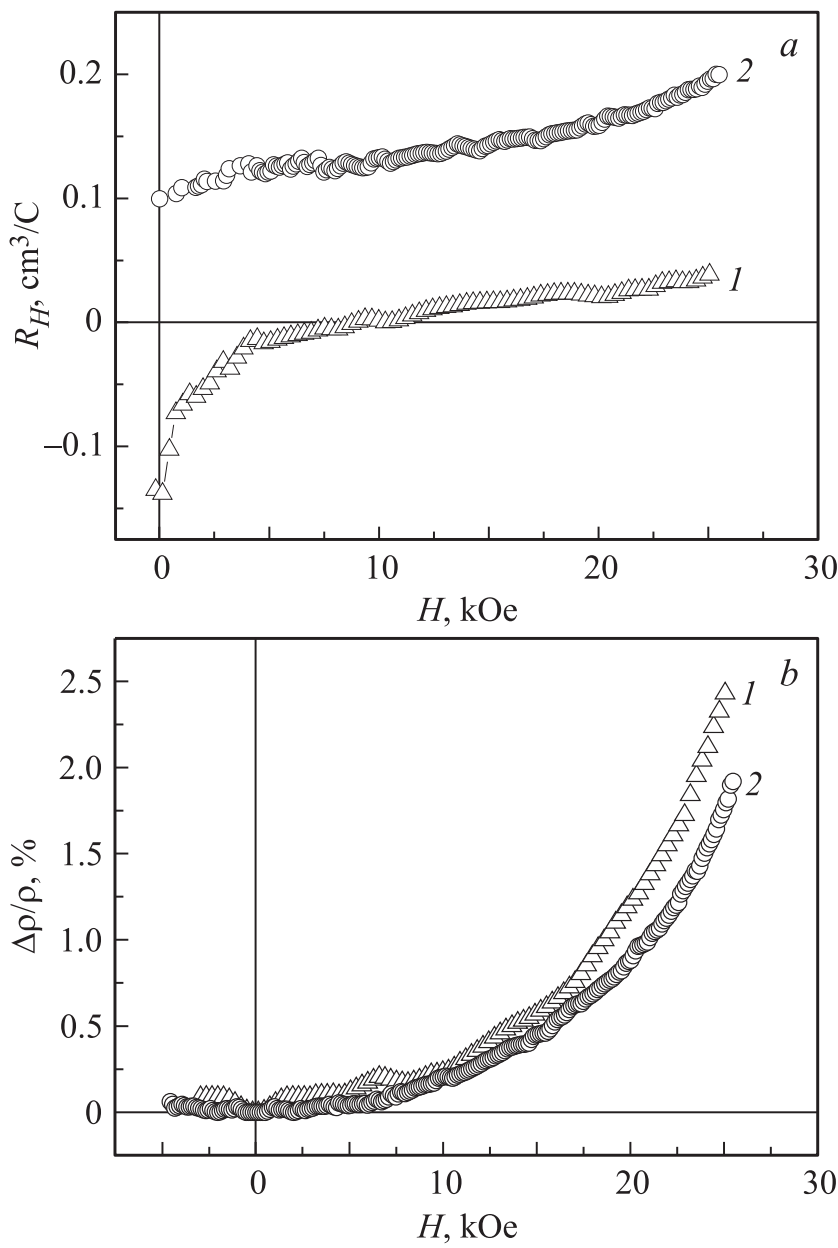

Рис. 2. Зависимость постоянной Холла $(a)$ и магнетосопротивления $(b)$ от напряженности магнитного поля для неотожженного образца состава $\mathrm{C}_{60}: \mathrm{TP}=1: 1$ при $300(1)$ и $77 \mathrm{~K}(2)$.
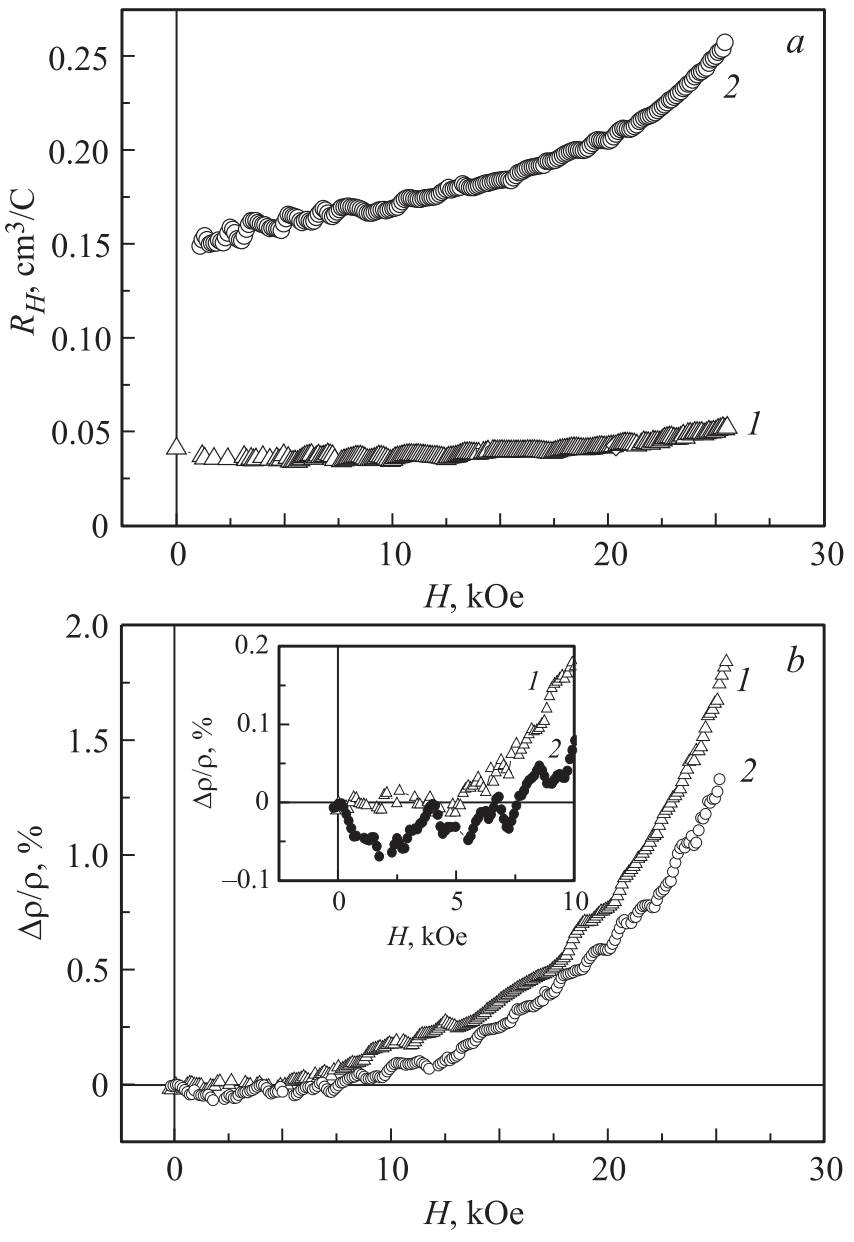

Рис. 3. Зависимость постоянной Холла $(a)$ и магнетосопротивления $(b)$ от напряженности магнитного поля для отожженного образца состава $\mathrm{C}_{60}:$ ТРГ $=1: 1$ при $T=300$ (1) и $77 \mathrm{~K}(2)$. На вставке начальные участки кривых, приведенных на части $b$, показаны в увеличенном виде.

отжига образцов, что уже отмечалось в [7]. Сами по себе значения $\rho$ невелики; иными словами, электропроводность образцов довольно высокая. Обращает на себя внимание форма кривых $\rho(T)$, на которых можно выделить несколько участков. На начальном участке (от $T=T_{\text {room }}$ и ниже) удельное сопротивление растет относительно медленно (штриховой линией на рис. 1 обозначен начальный наклон кривых), затем по мере дальнейшего снижения температуры скорость увеличивается, а при самых низких ее значениях рост $\rho$ опять замедляется, причем на некоторых кривых это выглядит как стремление к некой виртуальной константе, постоянному уровню.

На рис. 2 и 3 представлены зависимости $R_{H}(H)$ и $\Delta \rho / \rho$ для двух разных образцов одного состава, а именно: для неотожженного и подвергнутого отжигу образцов $\mathrm{C}_{60}: \mathrm{TP}=1: 1$. Видно, что коэффициент $R_{H}$ небольшой по величине и главным образом положителен, как и магнетосопротивление $\Delta \rho / \rho$. В других 
образцах картина аналогичная. Вместе с этим на рис. 2 и 3 имеются особенности. Так, в случае кривой 1 на рис. 2, $a$ постоянная Холла при $T=300 \mathrm{~K}$ отрицательна на начальном участке, а затем меняет знак. На кривой 2 pис. $3, b$ также на начальном участке, но уже при $T=77 \mathrm{~K}$ отрицательно магнетосопротивление, затем по мере роста напряженности поля оно становится положительным.

\section{4. Обсуждение результатов}

4.1. Типносителей заряда иих параметры. Полученные материалы можно отнести к графитоподобным ( $s p^{2}$-типа) системам. Среди таких систем наиболее совершенной структурой обладают, как известно [1], самые высококачественные природные графиты, в которых средние размеры кристаллов превышают величину $50 \mu \mathrm{m}$.

Напомним [8-11], что в монокристаллическом графите при $T=T_{\text {room }}$ удельное сопротивление вдоль двумерных базовых слоев, в пределах которых носители заряда полностью делокализованы, составляет величину $\rho_{a} \approx 10^{-4} \Omega \cdot \mathrm{cm}$, а поперек слоев $\rho_{c} \approx 1 \Omega \cdot \mathrm{cm}$; подвижность носителей заряда $\mu_{a} \approx 10^{4} \mathrm{~cm}^{2} \cdot \mathrm{V}^{-1} \cdot \mathrm{s}^{-1}$; концентрации электронов и дырок примерно одинаковые: $n_{e} \approx n_{h}=n=(6.2-7.9) \cdot 10^{18} \mathrm{~cm}^{-3}$, а отношение холловских подвижностей $\mu_{e} / \mu_{h}=1.09-1.12$, поэтому коэффициент Холла небольшой по абсолютной величине и отрицательный, а именно $R_{H} \approx 5 \cdot 10^{-2} \mathrm{~cm}^{3} \cdot \mathrm{C}^{-1}$. В целом графит не может быть описан как металл, поскольку число свободных электронов невелико ( $10^{-4}$ на атом), нет трехмерной металлической связи и трехмерно свободных электронов, поскольку перекрытие электронных орбит (и волновых функций электронов) соседних слоев слабое, откуда слабое $(\sim 0.04 \mathrm{eV})$ перекрытие зон (хотя оно и есть). Поэтому возникает полуметаллический энергетический спектр. В результате графит относят к компенсированным полуметаллам.

При увеличении степени структурного беспорядка уменьшаются размеры микрокристаллитов $L_{a}$, атомы в кристалле уходят со своих мест, в которых становятся доступными три валентности. Образуются вакансии, захватывающие электроны. Имея в виду $\pi$-электронное состояние утерянных атомов, можно ожидать, что каждая вакансия способна генерировать до трех избыточных дырок. Поэтому концентрация свободных носителей увеличивается, хотя их подвижность вследствие роста числа дефектов падает. При величинах $L_{a}$ порядка $100 \mathrm{~nm}$ зоны перестают перекрываться, при $L_{a}<100 \mathrm{~nm}$ появляется запрещенный зазор, уровень Ферми сдвигается вниз. Происходит трансформация из $n$-типа проводимости в $p$-тип, коэффициент Холла меняет знак с отрицательного на положительный.

В наших объектах, как уже отмечалось, коэффициент Холла главным образом положительный и небольшой по величине. Иными словами, основными носителями заряда являются дырки, концентрация которых довольно велика. В частности, в отожженном образце ТРГ без $\mathrm{C}_{60}$, а также в образцах со средним содержанием фуллеренов (состав $\mathrm{C}_{60}:$ ТРГ $=1: 1$ ) без отжига и с отжигом оценка величин $n_{h}$ при $T=77 \mathrm{~K}$ и $H=0$ дает значения $n_{h}=10.3 \cdot 10^{19}, 6.3 \cdot 10^{19}$ и $4.2 \cdot 10^{19} \mathrm{~cm}^{-3}$ соответственно, если использовать формулу

$$
R_{H}=1 / e n_{h},
$$

где $e-$ заряд электрона. Учитывая выражение для удельной проводимости

$$
\sigma=1 / \rho=e h_{n} \mu_{h},
$$

получаем соответствующие оценки подвижности: $\mu_{h}=27, \quad 14$ и $15 \mathrm{~cm}^{2} \cdot \mathrm{V}^{-1} \cdot \mathrm{s}^{-1}$. Иными словами, в чистом ТРГ параметры $n_{h}$ и $\mu_{h}$ выше, а рост электросопротивления при отжиге образцов происходит в основном за счет снижения концентрации подвижных носителей заряда. Можно предположить, что отжиг материала практически не влияет на механизм проводимости (форма кривых не меняется), а лишь создает дополнительные дефекты структуры вследствие разрыва некоторого количества химических связей из числа наиболее напряженных, возникающих при прессовании дисперсной смеси, и такие дефекты могут играть роль дополнительного эффективного канала захвата носителей заряда. Данное предположение подтверждается следующими фактами.

Как уже указывалось, согласно кривой 1 на рис. $2, a$, коэффициент $R_{H}$ изначально отрицателен, затем при увеличении напряженности магнитного поля меняет знак. Иными словами, в неотожженном образце при $T=300 \mathrm{~K}$ проявляются обе подсистемы носителей тока, причем в относительно малых полях основной является электронная подсистема, а в более сильных полях - дырочная. Для рассматриваемой кривой в точке $H=0$ по формулам типа (1) и (2) получается, что $n_{e}=4.6 \cdot 10^{19} \mathrm{~cm}^{-3}, \mu_{e}=26 \mathrm{~cm}^{2} \cdot \mathrm{V}^{-1} \cdot \mathrm{s}^{-1} \cdot$ В случае биполярной проводимости $R_{H}$, как известно [12], равен

$$
R_{H}=\frac{A}{e} \frac{n_{h} \mu_{h}^{2}-n_{e} \mu_{e}^{2}}{\left(n_{h} \mu_{h}+n_{e} \mu_{e}\right)^{2}},
$$

где $A=\mathrm{const} \approx 1$. Так что для точки $H=9 \mathrm{kOe}$, где $R_{H}=0$, согласно формуле (3), справедливо соотношение $n_{h} \mu_{h}^{2}=n_{e} \mu_{e}^{2}$. Учитывая зависимости $\sigma(T, H)$, в том числе тот факт, что $\sigma(0) \approx \sigma(H)$, получаем оценку $\mu_{e} \approx \mu_{h}$ (по поводу $\sigma(0) \approx \sigma(H)$ имеется в виду, что в точке $H=9 \mathrm{kOe}$ величина $\Delta \rho / \rho=0.2 \%$, см. кривую 1 на рис. $2, b$; следовательно, и изменение $\sigma$ здесь столь же незначительное). Иными словами, более подвижные при $T=300 \mathrm{~K}$ и $H=0$ электроны в присутствии магнитного поля замедляются в большей мере, чем дырки. При понижении температуры до $T=77 \mathrm{~K}$ (кривая 2 на рис. $2, a$, электроны вымораживаются сильнее, чем дырки, и это становится заметным, поскольку концентрации носителей тока с разным знаком различаются ненамного. Так 
что при более низкой температуре основными носителями тока становятся дырки. При этом на последней кривой остается „след“ от электронной подсистемы в виде едва заметного загиба вниз в полях от $H \approx 5 \mathrm{kOe}$ и ниже.

После отжига образца основными носителями становятся дырки также и при $T=300 \mathrm{~K}$, причем с параметрами $n_{h}=15.2 \cdot 10^{19} \mathrm{~cm}^{-3}$ и $\mu_{h}=7 \mathrm{~cm}^{2} \cdot \mathrm{V}^{-1} \cdot \mathrm{s}^{-1}$ при $H=0$ (рис. 3, $a$, кривая 1 ). Рост концентрации свободных дырок и снижение их подвижности подтверждают предположение о том, что после отжига появляются дополнительные ловушки, причем электронные, которые как новые дефекты структуры вносят свой вклад также и в рассеяние носителей, остающихся свободными. Электронным характером ловушечных центров можно объяснить также факт более сильного вымораживания более подвижных электронов. Наконец, электронный характер ловушечных центров соответствует оборванным ковалентным углеродным связям, поскольку для них характерен нескомпенсированный положительный заряд.

Повторимся, что при снижении температуры отожженного образца до $T=77 \mathrm{~K}$ в точке $H=0$ имеем $n_{h}=4.2 \cdot 10^{19} \mathrm{~cm}^{-3}, \quad \mu_{h}=15 \mathrm{~cm}^{2} \cdot \mathrm{V}^{-1} \cdot \mathrm{s}^{-1}$ (рис. 3, $a$, кривая 2), т.е. концентрация свободных носителей по сравнению с полученной при $T=300 \mathrm{~K}$ падает примерно в 3.5 раза, а подвижность почти вдвое возрастает. Данные обстоятельства можно объяснить тем, что ловушечные центры после захвата электронов становятся нейтральными, и их действие как центров рассеяния будет менее заметным.

Как отмечалось выше, сопротивление композитов монотонно растет с понижением температуры, т.е. температурный коэффициент сопротивления отрицателен, при этом температурная зависимость слабая, на кривых $\rho(T)$ не выполняется ,полупроводниковый“ активационный закон или закон Мотта для прыжковой проводимости. Электропроводность всех образцов довольно высокая, она преимущественно $p$-типа, но электронная подсистема также проявляется, при этом концентрация носителей заряда большая при невысокой их подвижности. Можно отметить также упоминавшееся в разделе 3 стремление величины $\rho$ на некоторых кривых $\rho(T)$ к постоянному уровню при достижении самых низких температур, что характерно для металлов, поскольку они обладают конечной остаточной проводимостью $\sigma(0)$. Хорошо известно также, что „металлический“ характер (электропроводность $n$-типа, положительный температурный коэффициент сопротивления) наблюдается в монокристаллических или почти монокристаллических графитах. В таких объектах за счет выравнивания ориентации микрокристаллитов, размеры которых могут достигать десятков микрометров и более, величины электросопротивления минимальны, а подвижности носителей заряда вдоль атомных сеток очень высоки. Так что с учетом всего этого полученные в настоящей работе композиты можно отнести к металлическим системам со структурным беспорядком типа „плохих“ металлов или вырожденных полупроводников.
В таких объектах, как хорошо известно (см., например, [12]), постоянная Холла от поля не зависит, а магнетосопротивление равно нулю, если имеются носители одного типа или они полностью доминируют. Однако в рассматриваемых материалах проявляются носители обоих типов (с разными знаками), поэтому и зависимость $R_{H}(H)$ имеет место, и $\Delta \rho / \rho \neq 0$, поскольку магнитное поле изменяет вклад носителей заряда различных типов в формирование поля Холла. В таких случаях в условиях слабых полей изменения коэффициента $R_{H}$ обусловлены в первую очередь более подвижными носителями заряда, которые могут проявляться сильнее, чем менее подвижные, и иногда доминировать даже при относительно небольшой собственной концентрации. Режим слабого поля подтверждается квадратичным по полю магнетосопротивлением, т. е. зависимостью $\Delta \rho / \rho \sim H^{2}$, наблюдаемой в эксперименте (рис. 2, $b$ и рис. $3, b)$. С ростом поля траектории более подвижных носителей тока, т.е. электронов, закручиваются все сильнее, уменьшается их вклад в поле Холла, наступает момент смены знака последнего (рис. 2, $a$, кривая 1).

Необходимо также отметить заметную роль электронов в формировании магнетосопротивления. Из данных рис. 2, $a$ и 3, $a$ следует, что влияние электронов на поле Холла существеннее при более высокой температуре. В неотожженном образце это выражено в явном виде (наличие участка, где $R_{H}<0, T=300 \mathrm{~K}$, рис. 2, a, кривая 1). В отожженном образце это проявляется в более низкой концентрации дырок при $T=300 \mathrm{~K}$, чем при $T=77 \mathrm{~K}$ (рис. $3, a$, кривые 1 и 2 ). В такой ситуации $\Delta \rho / \rho$ должно сильнее изменяться при $T=300 \mathrm{~K}$, чем при $T=77 \mathrm{~K}$, что и наблюдается экспериментально (рис. $2, b$ и рис. $3, b)$.

4.2. Форма кривых $\rho(T)$ и квантовые поправки к проводимости. Зависимости $\rho(T)$, по форме подобные изображенным на рис. 1, наблюдались и ранее во многих углеродных и неуглеродных объектах. Например, в пиролитических графитах $[8]$, Yb при фазовом переходе полуметалл-полупроводник (под давлением) [13], $\mathrm{SmB}_{6}$ [14], ультратонких сверхпроводящих гранулированных пленках $\mathrm{Pb}$ на $\mathrm{SiO}_{2}$ при их толщинах свыше $35 \AA$ [15], тонких (60-80 nm) пленках аморфного углерода на подложках из $n$-Si [3], высокопористом биоуглероде карбонизированного дерева бука [16] и т.д. Поскольку объекты самые разные, различны и механизмы переноса заряда, обеспечивающие характерный вид зависимостей $\rho(T)$. Так, в Үb эти механизмы обусловлены зонной структурой (незаполненными $d$-состояниями), а в $\mathrm{SmB}_{6}$, например, они связаны с металлической проводимостью в примесной полосе, образованной вакансиями $\mathrm{Sm}$.

У углерода своя специфика. Механизм проводимости даже в одних и тех же объектах, обработанных при разных температурах, может изменяться от зонного (т.е. по распространенным состояниям) до прыжкового по локализованным состояниям вблизи уровня Ферми, как это показано в [17]; в плохо проводящих структурах 
он может определяться даже токами, ограниченными пространственным зарядом [18]. Вместе с этим в литературе по углероду форма таких кривых $\rho(T)$, как на рис. 1, не всегда обсуждается в деталях.

Обычно считается, что в структурах, наиболее близких к графитам, преобладает рассеяние на фононах, концентрация которых при низких температурах падает, с чем связано замедление роста величины $\rho$ в этой области. В более аморфизированных образцах температурные вариации проводимости связываются с концентрацией свободных носителей. Имеется в виду, что с понижением температуры сопротивление растет за счет процесса изъятия последних. В области высоких температур скорость роста сопротивления при понижении температуры меньше, поскольку здесь начинает действовать фононное рассеяние. В структурах, где размеры микрокристаллитов в направлении базовых плоскостей становятся сравнимы или меньше средней термической длины свободного пробега (которая обратно пропорциональна плотности фононов), возрастает роль рассеяния на границах микрокристаллитов. В этом случае подвижность носителей заряда пропорциональна среднему размеру кристаллитов, кривизна зависимостей $\rho(T)$ отсутствует, т. е. они выглядят как практически горизонтальные прямые с очень слабым отрицательным наклоном.

Особенность наших зависимостей $\rho(T)$ состоит в том, что ни одной из них нельзя сопоставить какой-либо один закон $\rho=\rho(T)$, чтобы определить один конкретный механизм проводимости. Во всех температурных областях наблюдаются различные по характеру участки, плавно переходящие один в другой. Иными словами, в образцах одновременно могут реализоваться различные механизмы переноса носителей заряда, действовать разные источники их рассеяния.

Анализ показывает, что в области низких температур практически для всех составов выполняется зависимость $\sigma \sim T^{3 / 2}$, причем в разных образцах данный участок имеет несколько различающуюся длину по горизонтальной оси. Например, в образцах без $\mathrm{C}_{60}$ он простирается от $T=4.2 \mathrm{~K}$ до $T \approx 100 \mathrm{~K}$, в образцах с максимальным содержанием $\mathrm{C}_{60}$ - до $T \approx 90 \mathrm{~K}$. На рис. 4 для иллюстрации представлена электропроводность в координатах $\sigma-T^{3 / 2}$ для неотожженного и подвергнутого отжигу образцов состава $\mathrm{C}_{60}:$ ТР $=1: 1$. Видно, что, во-первых, экспериментальные точки при низких температурах хорошо укладываются на прямую, а во-вторых, участок $\sigma \sim T^{3 / 2}$ на рис. $4, a$ заканчивается при $T \approx 179 \mathrm{~K}$, а на рис. $4, b-$ при $T \approx 158 \mathrm{~K}$.

Хорошо известно, что закон $\sigma \sim T^{3 / 2}$ характерен для невырожденных полупроводников в том случае, когда преобладают заряженные рассеивающие центры (которыми обычно являются ионы примесей). Правда, еще в [19] замечено, что в подобных объектах данный закон трудно проверить в широком диапазоне температур, поскольку при высоких значениях $T$ преобладает рассеяние на колебаниях решетки (акустические фононы,
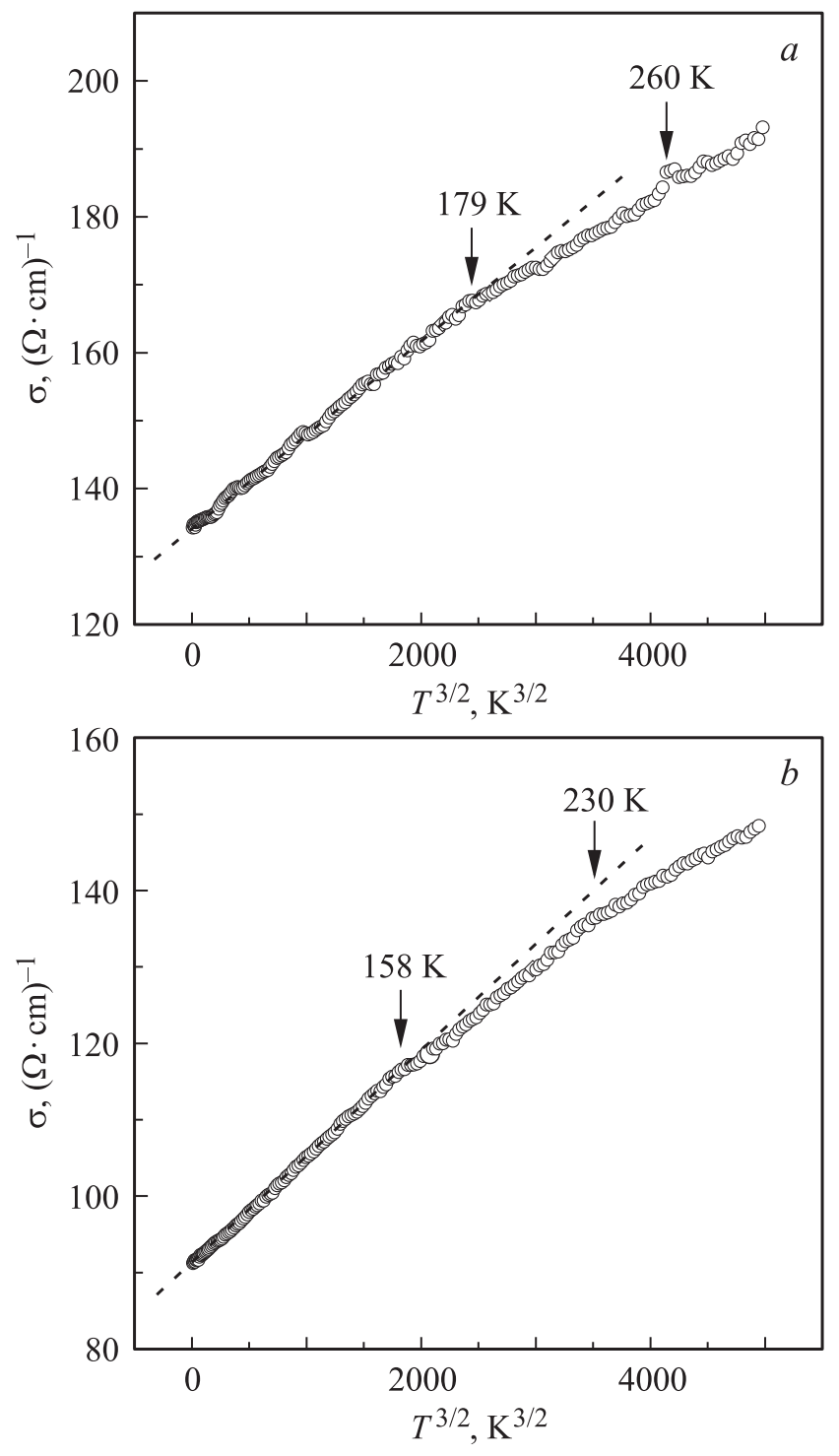

Рис. 4. Температурные зависимости удельной электропроводности образцов состава $\mathrm{C}_{60}: \mathrm{TP} \Gamma=1: 1$ в координатах $\sigma-T^{3 / 2}$. $a$ - неотожженный образец, $b-$ отожженный образец. Штриховыми прямыми показана аппроксимация низкотемпературных областей; стрелками обозначены видимые границы различных температурных участков.

$\sigma \sim T^{-3 / 2}$ ), а при низких $T$ носители вымораживаются на уровни примесей, так что концентрация ионов становится зависящей от температуры по экспоненте.

В нашем материале заряженных центров должно быть довольно много, особенно в отожженных образцах, что уже отмечалось в предыдущем подразделе. Однако исследуемый композит, во-первых, представляет собой среду металлического типа; во-вторых, в неотожженном образце участок $\sigma \sim T^{3 / 2}$ продолжается до более высокой температуры $(T \approx 179 \mathrm{~K})$, чем в образце, подвергнутому отжигу, где аналогичный участок заканчивается при $T \approx 158 \mathrm{~K}$. Если бы закон $\sigma \sim T^{3 / 2}$ в образцах был обусловлен рассеянием носителей на заряженных 
центрах, то должно было бы быть наоборот: протяженность участка, где выполняется закон $\sigma \sim T^{3 / 2}$, должна быть больше в отожженном образце, поскольку в нем концентрация заряженных центров выше. Кроме того, в отожженном образце состава $\mathrm{C}_{60}:$ ТРГ $=1: 1$ зафиксировано отрицательное магнетосопротивление (рис. $3, b$ ). Его обычно наблюдают в металлических средах со структурным беспорядком и интерпретируют в рамках квантовых интерференционных эффектов [20,21]. Отметим, что отрицательное магнетосопротивление $\Delta \rho / \rho$ в принципе может наблюдаться также за счет спиновых эффектов, однако для этого, как хорошо известно, требуются магнитные примеси. В исследуемый материал они специально не вводились и присутствуют здесь случайно в следовых количествах, как показал рентгеновский микроанализ образцов.

В трехмерном варианте температурные зависимости квантовых поправок к проводимости $\Delta \sigma(T)$ можно выразить следующим образом:

$$
\Delta \sigma(T)=\sigma(T)-\sigma(0)=\alpha_{\mathrm{loc}} T^{p / 2}+\beta_{e-e} T^{1 / 2},
$$

где первое слагаемое в правой части дают эффекты слабой локализации, второе возникает за счет электронэлектронных взаимодействий; $\alpha_{\mathrm{loc}}, \beta_{e-e}$ и $p-$ коэффициенты. Первые два вычисляются для каждого конкретного материала, для чего необходимо знать довольно много параметров, $p$ определяется механизмом сбоя фазы волновой функции носителя заряда при его рассеянии.

Если уравнение (4) использовать для описания наших зависимостей $\sigma(T)$, то для области низких температур хорошо подходит величина $p=3$. Это характерно для сбоя фазы волновых функций носителей заряда вследствие столкновений с фононами.

Что касается областей средних и высоких температур, то закон $\sigma=\sigma(T)$ однозначно идентифицировать удалось не во всех образцах, вероятно из-за одновременного действия нескольких факторов, влияющих на процессы переноса заряда. Вместе с тем в большинстве образцов можно различить главным образом по два участка. В частности, на рис. 4, $a$ эти участки располагаются при температурах $T=179-260 \mathrm{~K}$ и $260 \mathrm{~K}-T_{\text {room }}$, на рис. $4, b$ - при $T=158-230 \mathrm{~K}$ и при $230 \mathrm{~K}-$

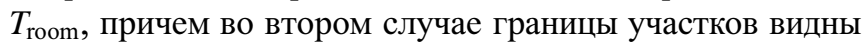
вполне отчетливо даже в мелком масштабе. Указанные участки, как правило, укладываются на прямую $\sigma \sim T^{1 / 2}$, но характеризуются разным наклоном. Иными словами, в области средних и высоких температур локализационные эффекты уступают место электронэлектронным взаимодействиям. С ростом температуры увеличиваются концентрации фононов и электронов, высвобождающихся с ловушек. Вероятно, при средних и высоких температурах неупругие межэлектронные взаимодействия становятся более действенными в смысле сбоя фазы, чем квазиупругие столкновения электронов с фононами.
Поскольку зависимость $T^{3 / 2}$ более сильная, чем $T^{1 / 2}$, можно предположить, что при низких температурах либо коэффициенты $\alpha_{\mathrm{loc}}$ и $\beta_{e-e}$ близки по величине, либо $\alpha_{\mathrm{loc}}$ несколько превалирует над $\beta_{e-e}$. С ростом температуры ситуация меняется на обратную, причем в областях средних и высоких температур значения коэффициента $\beta_{e-e}$ могут быть разными.

4.3. Влияние содержания фуллеренов на свойства композита. Если вернуться к рис. 1, то можно заметить, что форма кривых $\rho(T)$ примерно одинакова для всех образцов (без фуллеренов, с невысоким, средним и относительно большим их содержанием). Поэтому есть основания полагать, что эта особенность определяется главным образом углеродной матрицей, в которой размещается $\mathrm{C}_{60}$, а также характером и параметрами технологии.

Присутствие фуллеренов сказывается на величине электрического сопротивления материала, которое зависит от концентрации и подвижности носителей заряда. Соответствующие данные по ряду образцов представлены в таблице.

Видно, что максимальные величины электропроводности, концентрации и подвижности наблюдаются при нулевом или минимальном содержании фуллеренов. $\mathrm{C}$ ростом концентрации $\mathrm{C}_{60}$ указанные параметры снижаются, причем для крайних составов $\left(\mathrm{C}_{60}: \mathrm{TP}=1: 16\right.$ и $16: 1)$ это снижение происходит быстрее, чем уменьшение относительной доли ТРГ (или, что то же самое, увеличение доли $\mathrm{C}_{60}$ ).

Хорошо известно, что сами по себе молекулярные фуллереновые конденсаты являются плохо проводящими полупроводниками $n$-типа с шириной запрещенной зоны $1.5-2 \mathrm{eV}$, в которых величина $\rho$ может достигать значений $\sim 10^{14} \Omega \cdot \mathrm{cm}[22]$. Однако в пределах каждой молекулы $\mathrm{C}_{60} 60 \pi$-электронов находятся на почти полностью делокализованных молекулярных орбиталях, охватывающих весь углеродный каркас. Иными словами, эти электроны почти свободно двигаются в поле 60 ионов $\mathrm{C}^{+}$по замкнутым траекториям, и здесь в отличие от графитовых систем ни о каких свободных дырках, разумеется, не может быть и речи. Поэтому при участии таких электронов в сквозных токах через общую структуру $\mathrm{C}_{60}+$ ТРГ возможны компенсационные эффекты. Последние будут иметь место при условии, что молекулы $\mathrm{C}_{60}$ (или их небольшие блоки) имеют с углеродной матрицей ковалентные связи, что под-

Параметры ряда отожженных образцов при различном содержании фуллеренов, $T=77 \mathrm{~K}$

\begin{tabular}{c|c|c|c|c}
\hline \multirow{2}{*}{ Параметр } & \multicolumn{4}{|c}{ Соотношение $\mathrm{C}_{60}:$ ТРГ } \\
\cline { 2 - 5 } & - & $1: 16$ & $1: 1$ & $16: 1$ \\
\hline Содержание $\mathrm{C}_{60}$, mass\% & 0 & 6 & 50 & 94 \\
$\rho, m \Omega \cdot \mathrm{cm}$ & 2.28 & 2.58 & 8.06 & 335.73 \\
$n_{h}, 10^{19} \mathrm{~cm}^{-3}$ & 10.3 & 6.8 & 4.2 & 0.38 \\
$\mu_{h}, \mathrm{~cm}^{2} \cdot \mathrm{V}^{-1} \cdot \mathrm{s}^{-1}$ & 27.0 & 33.0 & 15.0 & 1.2
\end{tabular}


тверждается экспериментально [7]. При сквозных токах дефектами структуры в такой общей системе помимо собственных дефектов прессованного ТРГ и неконтролируемых примесей будут пентагоны в фуллереновых каркасах и химические связи различного типа, объединяющие молекулы $\mathrm{C}_{60}$ друг с другом и с матрицей.

При указанных обстоятельствах с ростом содержания фуллеренов могут усиливаться компенсационные эффекты, а среднее время между элементарными актами рассеяния свободных носителей заряда падать. Иначе говоря, снижение измеряемых концентраций и подвижностей носителей заряда может быть более быстрым, чем снижение в материале доли ТРГ, что и наблюдается в эксперименте.

\section{5. Заключение}

Исследованы кинетические процессы в предложенных ранее углеродных композиционных материалах на основе фуллеренов и терморасширенного графита при девяти исходных соотношениях $\mathrm{C}_{60}$ :ТРГ, равных $1: 16$; $1: 8 ; 1: 4 ; \ldots ; 16: 1$ по массе. Образцы получены путем термообработки в вакууме в диффузионно-адсорбционном процессе исходных дисперсных смесей в течение нескольких часов при температурах $550-650^{\circ} \mathrm{C}$, их дальнейшего холодного прессования и отжига.

Выявленные параметры процессов и наблюдающиеся эффекты позволяют отнести материалы к графитовым системам типа „плохих“ металлов или сильно легированных (вырожденных) полупроводников.

Основными носителями заряда являются дырки, что традиционно для графитоподобных систем, но при этом проявляются и электроны.

Отжиг материала практически не влияет на механизмы проводимости, а лишь создает дополнительные дефекты структуры, вероятно вследствие разрыва некоторого количества химических связей из числа наиболее напряженных, возникающих при прессовании дисперсной смеси. Такие дефекты играют роль ловушечных центров как дополнительного эффективного канала захвата свободных электронов.

Перенос заряда управляется квантовыми интерференционными явлениями, причем в области низких температур более заметны эффекты слабой локализации, в области средних и высоких - электрон-электронных взаимодействий.

Максимальные величины электропроводности, концентрации и подвижности наблюдаются в чистом прессованном ТРГ и в композите при минимальном содержании фуллеренов. С ростом концентрации $\mathrm{C}_{60}$ указанные параметры снижаются быстрее, чем можно было бы ожидать, что можно объяснить усилением компенсационных эффектов и падением среднего времени релаксации рассеяния свободных носителей заряда.

Автор благодарит В.В. Попова за полезные дискуссии.

\section{Список литературы}

[1] В.И. Березкин. Углерод: замкнутые наночастицы, макроструктуры, материалы. АРТЭГО, СПб (2013). 450 с.

[2] В.И. Березкин. Введение в физическую адсорбцию и технологию углеродных адсорбентов. Виктория плюс, СПб (2013). 409 c.

[3] Q.Z. Xue, X. Zhang. Carbon 43, 760 (2005).

[4] O. Gunnarson. Rev. Mod. Phys. 69, 575 (1997).

[5] В.И. Березкин. Письма в ЖЭТФ 83, 455 (2006).

[6] В.И. Березкин, В.В. Попов. ФТТ 49, 1719 (2007).

[7] В.И. Березкин, В.В. Попов, М.В. Томкович. ФТТ 59, 601 (2017).

[8] C.A. Klein. Rev. Mod. Phys. 34, 56 (1962).

[9] Краткая химическая энциклопедия / Под ред. И.Л. Кнунянца. Сов. энциклопедия, М. (1967). Т. 5. 590 с.

[10] M.S. Dresselhaus, G. Dresselhaus. Adv. Phys. 30, 139 (1981).

[11] С.В. Шулепов. Физика углеродных материалов. Металлургия, Челябинск (1990). 336 с.

[12] П.С. Киреев. Физика полупроводников. Высш. шк., М. (1975). $584 \mathrm{c}$.

[13] D.B. McWhan, T.M. Rice, P.H. Schmidt. Phys. Rev. 177, 1063 (1969).

[14] J.C. Nickerson, R.M. White, K.N. Lee, R. Bachmann, T.H. Geballe, G.W. Hull, Jr. Phys. Rev. B 3, 2030 (1971).

[15] H.M. Jaeger, D.B. Haviland, B.G. Orr, A.M. Goldman. Phys. Rev. B 40, 182 (1989).

[16] Л.С. Парфеньева, Т.С. Орлова, Н.Ф. Картенко, Н.В. Шаренкова, Б.И. Смирнов, И.А. Смирнов, Н. Misiorek, A. Jezowski, T.E. Wilkes, K.T. Faber. ФTT 52, 1045 (2010).

[17] В.В. Попов, Т.С. Орлова, Е. Enrique Magarino, М.А. Bautista, J. Martinez-Fernandez. ФTT 53, 259 (2011).

[18] I. Lazar, G. Lazar. J. Non-Cryst. Solids 352, 2096 (2006).

[19] K. Seeger. Semiconductor physics. Springer-Verlag, WienN.Y. (1973). XV+514 p. [К. Зеегер. Физика полупроводников. Мир, М. (1977). 615 с.].

[20] B.I. Altshuler, A.G. Aronov. In: Electron-electron interactions in disordered systems. Ser. Modern problems in condensed matter science. V. 10 / Eds A.L. Efros, M. Pollak. NorthHolland, Amsterdam, etc. (1985). P. 1.

[21] P.A. Lee, T.V. Ramakrishnan. Rev. Mod. Phys. 57, 287 (1985).

[22] Т.Л. Макарова. ФТП 35, 257 (2001). 